
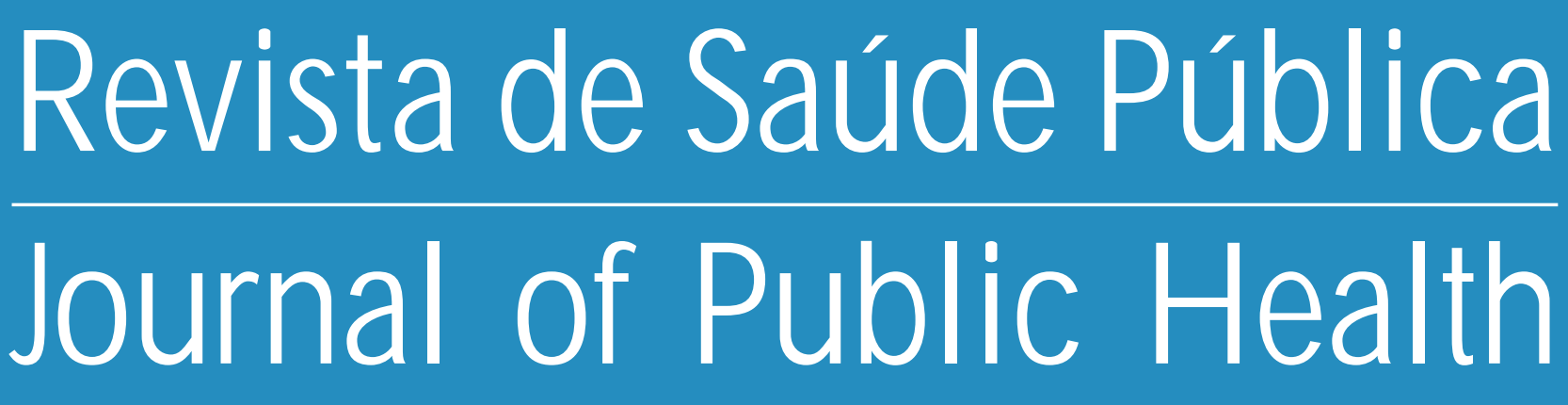

Current Comments

Atualização

\title{
Child-care attendance and common morbidity: evidence of association in the literature
}

\section{and questions of design*}

Freqüência a creches e morbidade comum

na infância: evidência de associação

na literatura e problemas de delineamento

\section{Aluísio J. D. Barros}

Departamento de Medicina Social da Universidade Federal de Pelotas. Pelotas, RS - Brasil 


\title{
Child-care attendance and common morbidity: evidence of association in the literature and questions of design*
}

Freqüência a creches e morbidade comum na infância: evidência de associação na literatura e problemas de delineamento

\author{
Aluísio J. D. Barros \\ Departamento de Medicina Social da Universidade Federal de Pelotas. Pelotas, RS - Brasil
}

\section{Keywords}

Respiratory tract infections, epidemiology.

Diarrhea, epidemiology. Risk factors. Child day care centers.

\section{Descritores}

Infecções respiratórias, epidemiologia. Diarréia, epidemiologia. Fatores de risco. Creches.

\begin{abstract}
Papers on child-care attendance as a risk factor for acute respiratory infections and diarrhea were reviewed. There was great variety among the studies with regard to the design, definition of exposure and definition of outcomes. All the traditional epidemiological study designs have been used. The studies varied in terms of how child-care attendance in general was defined, and for different settings. These definitions differed especially in relation to the minimum time of attendance required. The outcomes were also defined and measured in several different ways. The analyses performed were not always appropriate, leading to sets of results of uneven quality, and composed of different measures of association relating different exposures and outcomes, that made summarizing difficult. Despite that, the results reported were remarkably consistent. Only two of the papers reviewed failed to show some association between child-care attendance and increased acute respiratory infections, or diarrhea. On the other hand, the magnitude of the associations reported varied widely, especially for lower respiratory infections. Taken together, the studies so far published provide evidence that children attending child-care centers, especially those under three years of age, are at a higher risk of upper respiratory infections, lower respiratory infections, and diarrhea. The studies were not consistent, however, in relation to attendance at child-care homes. Children in such settings were sometimes similar to those in child-care centers, sometimes similar to those cared for at home, and sometimes presented an intermediate risk.
\end{abstract}

\section{Resumo}

Foram revisados artigos sobre freqüencia a serviços de cuidado infantil (não residencial) e sua associação com infecções respiratórias e diarréia. Encontrouse grande variação entre os estudos em relação ao seu desenho e à definição das exposições e desfechos. As análises realizadas não foram sempre adequadas, levando a um conjunto de resultados de qualidade desigual, composto de 
diferentes medidas de associação ligando exposições e desfechos diferentes, $e$ de difícil sumarização. Apesar das diferenças, os estudos se mostraram consistentes no sentido de associar a freqüência a creches com um maior risco de infecções respiratórias e diarréia. Por outro lado, a magnitude das associações encontradas variou bastante. Com relação a creches residenciais, no entanto, os resultados são conflitantes. Alguns estudos encontraram que crianças nestas creches são semelhantes às cuidadas em casa, outros que elas são semelhantes às que freqüentam creches e ainda outros que encontraram riscos intermediários entre os dois grupos.

\section{INTRO DUCTION}

In the developed world, a large and variable proportion of preschool children are attending different forms of out-of-home child care. Child-care centers, institutional settings where children are cared for during the day, usually in a school-like structure, play a central role in this scenario. It has been estimated that, in the US the proportion of children under 6 years of age attending child-care centers ranges between $16 \%^{14,26}$ and $22 \%{ }^{17}$. A proportion of $11 \%$ was reported for New South Wales, Australia, in $1991^{20}$. Higher proportions are found in countries that run large child-care programs, such as Sweden, where it has been estimated that $32 \%$ of all preschool children attend municipal child-care centers alone ${ }^{28}$.

Less information is available for the developing countries especially relating to services other than child-care centers. In Brazil, the proportion of children attending child-care centers in a few cities has been estimated for the present study on the basis of data from the local authorities and the 1991 National Census. In Fortaleza, in the poorer Northeastern region, approximately $5 \%$ of preschool children were found to be attending free (public and philanthropic) child-care centers (data from the State Secretariat of Social Welfare). In Campinas and S. Paulo, in the Southeast, it was estimated that $13 \%$ and $10 \%$ of the preschool children were attending free child-care centers (data from the Campinas Municipal Education Secretariat, and the S. Paulo Municipal Social Welfare Office). In Pelotas, where a survey has recently been finished, the number of children in child-care centers represented $14 \%$ of the preschool population: $8 \%$ in free child-care centers, and $6 \%$ in private child-care centers (author's unpublished data).

The quality and type of care provided for the children has been an object of concern and study for many years, the first studies in the health area dating from the late $1940 \mathrm{~s}^{8,15,21}$. Children under child care and the care providers have been studied within several different perspectives: psychological, developmental, educational, and economic.

Epidemiological studies of the health effects of outof-home care, however, are not numerous. Nearly all of them have been undertaken in developed countries, specially in the US and Scandinavia. Although most suggested that children attending child-care centers were at a higher risk of infections than those cared for at home, in several studies the results cannot be taken at face value because of design and analysis problems. The questions most frequently addressed were whether children attending child-care centers were at a higher risk of common childhood infections, such as respiratory infections and diarrhea. Papers published since the seventies that covered these outcomes have been reviewed in the present work.

\section{CHILD-CARE ATTENDANCE AND CHILD MORBIDITY}

\section{Upper Respiratory Infections (URI)}

A review by Haskins \& Kotch ${ }^{14}$ concluded that studies published prior to that date agreed on attributing greater risk of upper respiratory infections to children enrolled in child-care centers, although no evidence of a similar association with lower respiratory infections (LRI) was provided. Younger children, especially infants, were the groups identified as being at the greatest risk. The readers were warned, however with regard to the great difficulty experienced in reviewing the papers, mainly due to the different age ranges studied and the variety of age groupings, the variety of definitions used for respiratory infections, and design flaws resulting in inadequate comparison groups.

Indeed, those studies had the merit of being pioneers in the area, but had considerable design problems, making it difficult to draw firm conclusions from them. For instance, one study used an external comparison group ${ }^{22}$, another used 
different methods to collect data from children in child care and children cared for at home $\mathrm{e}^{30}$ and another had a very small sample size, with children in child care coming from only one center ${ }^{9}$. More recent studies have improved their methods, but there are still many problems, as discussed in a later section.

The study designs used include all the standard epidemiological designs, and the definitions of childcare attendance and risk factors varied widely. The result is a collection of different measures of association relating slightly different exposures and risk factors, presenting a real challenge to the reviewers who wish to correlate the results.

All the studies $6,7,10,19,23,27,33,34$ but two ${ }^{4,12}$ found an increased risk of URI among children attending childcare centers. Despite the variety of methods used, the relative risks reported did not vary widely, most studies reporting a relative risk below two.

Two cross-sectional studies undertaken in the US looked at the 2-week period prevalence of acute respiratory infections (ARI) among children 0-59 months of age ${ }^{10,19}$. The main exposure studied was child care attendance defined as care with at least one unrelated child for at least 4 hours per week by Fleming et al. ${ }^{10}$ and for at least 10 hours per week by Hurwitz et al. ${ }^{19}$ Both studies reported an adjusted prevalence ratio of 1.6 comparing children in child care with children cared for at home. This result applied to all children in Fleming's study ${ }^{10}$. Hurwitz et al. ${ }^{19}$ reported an interaction between age and siblings: children aged 1-17 months had a prevalence ratio of 1.6, while children 18-35 months of age had a prevalence ratio of 3.4 if they had no siblings and were not at an increased risk if they had siblings.

Two one-year historical cohort studies were conducted in Scandinavia by Petersson et al. ${ }^{27}$ and Louhiala et $\mathrm{al}^{23}$. In one study ${ }^{27}$, morbidity information of children aged 1-3 years was collected from medical records, and attendance at child-care centers and child-care homes was informed by the local authority. No other information about the children was available, and no potential confounders were controlled for. The other study ${ }^{23}$ included children 1-7 years old and all the information was collected from the parents, by mailed questionnaires, covering the past 12 months. The first study reported a crude relative risk of $1.58(1.28-1.95)$ comparing ARI incidence between child care center and home-cared children. The second study found age to modify the effect of child care center attendance. Children aged 1 in child care centers had a relative risk of 1.7 (1.42.0), children aged 2 had a relative risk of 1.2 (1.01.5 ), and children over 2 years old did not differ from children cared for at home. In Petersson's study, children in child-care homes had an intermediate risk relative to those under home care and in child-care centers $(\mathrm{RR}=1.3 ; 95 \% \mathrm{CI}=1.0-1.6)$. Louhiala found no difference between child-care homes and home care. The main problems with Petersson's study were the lack of control for potential confounders, and probably the quality of information collected from records. The latter problem seems to be even more serious in the study by Louhiala et al as 12 months is a very long recall period, especially considering that the questionnaires were sent by mail and no interviewer was there to help recollections. Also, there was a non-response rate of $20 \%$.

A further historical cohort was built by Collet et al. ${ }^{7}$ with the information collected at the entry interview of a cohort study carried out in France. The objective was to assess the effect of enrolment in child care on the first occurrence of URI with fever, wheezy bronchitis and acute otitis media. Children were matched by age at 3, 5, 7 and 9 months of age and those who had just started child care were compared with the ones who had not yet been enrolled in child care, using morbidity information from the 2 subsequent months. Children at 3, 5 and 7 months of age were found to have a higher risk (1.7, 2.1 and 2.4 respectively) of a first episode of URI with fever in the first 2 months of enrolment. The way the data were assembled, however, allowed for different recall periods as the ages varied at the time of recruiting for the study. Also, the very start of young children in child care probably offers a potential for recall bias, as parents will be especially attentive to their children's health.

Among the studies using a prospective cohort design, all but one reported the mean number of episodes occurring during the follow-up period as the measurement of occurrence. Gardner et al. ${ }^{12}$ were the only authors to report the results of their oneyear follow-up study as incidence rates, but relative risks were not presented. The 131 children in the study were visited weekly at home, from birth to 12 months of age. Different child-care settings were assessed conjointly, and no association with URI was 
found (the relative risk for URI was 1.2, as calculated from a table). Significant results concerning LRI were found and are discussed in a later section.

Bell et al. ${ }^{4}$ were interested in morbidity and costs of medical care as associated with child-care attendance. Using linear regression to model the number of illness episodes, and controlling for socioeconomic and demographic factors, no association between child-care home attendance and URI, LRI, otitis media, or diarrhea was found. As regards child-care centers, the only significant association found was with otitis media. The mean monthly cost of the care of child-care center children, perhaps the outcome best measured by this study, was $83 \%$ above that for home children, mainly due to the higher frequency of tympanostomy tube placements in this group. In general, the risks found for children in child-care homes were intermediate in relation to home care and child-care centers.

A similar finding was reported by Wald et al. ${ }^{33}$, in a three-year follow-up study. The data were analyzed separately for each year, and the same pattern was found for each follow-up year. Relative risks for URI abstracted from the graphs are around 1.6 for child-care center children relative to home children. No relative risks or confidence intervals were reported in the paper, and significance tests are difficult to interpret as comparisons between child care settings for each follow-up year were made by means of multiple independent t-tests, inappropriate in the circumstances. Also, no control of potential confounders was attempted.

A third cohort study was carried out in France, by Collet et $\mathrm{al}^{6}$, primarily to assess the effect of different types and sizes of child care settings on the occurrence of repeated infections in the children. Differently from other studies, children in child-care homes were used as the comparison group, as the data for home children were not comparable to those for the other groups. In fact, data were also collected in slightly different ways for children in child-care centers and child-care homes. Relative risks were not reported. The general tendency found in the study was for higher risks of repeated infections (URI, otitis media, and diarrhea, among others) among children in small child-care centers $(<40$ children) compared to children in child-care homes. Children in large centers (> 40 children) had risks closer to children in child-care homes. Two possible explanations must be considered when interpreting these results. Firstly, for all centers, there was only one person responsible for assessing and recording morbidity, which may have led to under-reporting in the larger centers. Secondly, the participating centers were selected for their convenience and self-reported ability to cope with the study, which may have led to some selection bias. Other possible explanations, as argued by the authors, are the better quality of service offered by the larger centers, the use of purpose-built buildings and the organization of the children into classes of similar ages.

One case-control study, by Woodward et al. ${ }^{34}$ in Australia, used a survey responded to by 2,618 households (53\% of those contacted replied) which inquired about the occurrence of respiratory diseases in 0-6 year-old children in the previous 12 months to identify cases and controls. Based on the answers, children in the upper and lower quintiles of the resulting distribution were classified as being "prone" (cases) or "not prone" (controls) to respiratory illnesses. Both regular and occasional child-care attendance were associated with higher "proneness" to respiratory illness, with odds ratios respectively of 2.9 and 1.8. However, as pointed out in a letter ${ }^{31}$, there were indications of selection and information bias, suggested by the poor response rate, the much higher proportion of children in child care in the study than in official estimates, and the fact that less than $25 \%$ of the original sample was interviewed at home.

Despite the variability in terms of study designs and definitions of outcomes and exposures, these studies taken together provide convincing evidence that children attending child care, and especially child-care centers, are at a moderately higher risk of URI than children cared for at home. In relation to children attending child-care homes, however, the results are less clear. From the five studies that reported risks separately for child-care centers and child-care homes ${ }^{4,6,23,27,33}$, three of them found that child-care homes presented an intermediate risk ${ }^{6,27,33}$, between child-care centers and home care, one found similar risks for home care and child-care homes ${ }^{23}$, and one found no association at $\mathrm{al}^{4}$. Taken together, these studies suggest that child-care homes offer a lower risk of URI than child-care centers, although stronger evidence of where this risk lies in relation to home care is still lacking. 


\section{Lower Respiratory Infections (LRI)}

Three cohort and three case-control studies reporting on the association between LRI/pneumonia and child-care attendance were identified. The cohort studies were based on birth cohorts that were followed for one year ${ }^{12}$, two years ${ }^{24}$ or three years ${ }^{18}$. The first study, by Gardner et al. ${ }^{12}$ (1984), enrolled 131 children, and detected illness by means of frequent home visits. Diagnoses were made by medical personnel and child-care attendance was defined as consistent attendance for at least 5 months at child-care centers or mother's day out. The other two studies recruited significantly more children (approximately 1,200) who were enrolled in a health maintenance organization. Diagnoses were made by physicians seeing the children at the clinic. In both studies details of child-care attendance such as type of setting, number of unrelated children present, and smoking were explored.

Gardner et al. ${ }^{12}$ reported a significant crude association between LRI and child-care attendance ( $R R=1.4, p=0.01$, calculated from the table). The occurrence of pneumonia was approximately fourfold in the child-care group, but significance was not achieved probably due to the small number of episodes recorded. Adjusted analyses were not reported. Marbury et $\mathrm{al}^{24}$ found an overall relative risk of 2 for children in child care. The adjusted relative risks found for care at own home (with someone other than the parents), child-care homes and child-care centers were 1.7 (1.4-2.1), 2.0 (1.72.3 ) and 2.3 (1.9-2.8). The increase in risk did not vary substantially with group size either. Similarly, Holberg et $\mathrm{al}^{18}$ did not find any clear association of LRI with child-care setting or group size. Reported odds ratios referred to children in out-of-home care with 3 or more unrelated children. The adjusted odds ratios found were $2.13(1.1-4.1)$ for children $0-3$ months, 2.23 (1.3-3.7) for children 4-6 months, 1.65 (1.1-2.5) for children 6-12 months, 1.58 (1.1-2.2) for children 1-2 years, and 2.04 (1.4-3.0) for children $2-3$ years old. An odds ratio for all ages was not reported, nor was any test for interaction between exposure and age.

The first of the 3 case-control studies was based on four hospitals in Atlanta (USA), where the parents of cases (children admitted to hospital with pneumonia or bronchiolitis) and age/sex-matched controls were interviewed by telephone shortly after admission ${ }^{2}$. The odds ratio for children attending child-care centers (adjusted for several potential confounders) was $2.96(\mathrm{p}<0.05)$ relative to children cared for at home. Children attending child-care homes were not at a significantly higher risk than those in home care (adjusted $\mathrm{OR}=1.13, \mathrm{p}>0.05$ ).

The other 2 case-control studies were carried out in Brazil, based on similar protocols, to study risk factors for pneumonia. The cases were identified in hospitals, and the diagnosis of pneumonia was established by X-rays. The controls were identified from the neighborhood of each case, and matched by age. One was carried out in Fortaleza ${ }^{11}$, in the Northeast, by the sea and very near to the Equator. The other took place in Porto Alegre ${ }^{32}$, in the subtropical South of Brazil.

In Fortaleza, the odds ratio for attendance at child care facilities compared to home care was 5.2 (2.112.8; adjusted for income and parental education). In Porto Alegre, the OR for child-care center attendance (adjusted for father's education, age and sex) was 11.8 (5.2-26.5). The difference between these studies is striking, especially because the higher risk was found in the wealthier area. The cases were verified by the same radiologist, but there may have been some variation in the definition of child-care attendance, which was not clearly defined in either report of the studies and may not have been clearly defined to the respondents. It seems unlikely, however, that such possible variations might account for the difference in the magnitude of risks. Longer periods spent indoors and less ventilation in Porto Alegre, resulting from the colder climate seem to be the most likely explanations. Another source of bias, however, must be considered. Given that the cases were selected in the pediatric outpatient clinics of hospitals, it may be that a larger proportion of mothers who have children in child-care centers seek medical care at the hospitals compared with those who keep their children at home, who may favor the local health centers. This may be the case by the conjunction of two factors. Firstly, most mothers of children in child care work outside the home, and consequently are busy for most of usual working hours. Secondly, in Brazil, the hospitals run clinics working 24 hours a day and these might be more accessible to the working mothers than the local health centers that usually close by 6 p.m. Finally, it is important to consider that the confidence intervals in both studies 
are quite wide, as the proportion of children in child care was relatively small $(1.2 \%$ and $2.7 \%$ in the control group in Fortaleza and Porto Alegre respectively).

The studies are consistent in attributing a higher risk of LRI or pneumonia to children attending child care, and provide convincing evidence of such an association. The studies carried out in the US found somewhat lower risks than those in Brazil. It may be that child care is indeed associated with higher risks in developing countries than in developed countries. But results are not directly comparable, and the possible biases discussed above must be taken into account. A study designed specifically to assess the magnitude of this association is still lacking in the literature.

The relative position of child-care homes relative to child-care centers, as before, is unclear. Anderson et al. ${ }^{2}$ did not find any association between LRI and child-care homes, while Marbury et al. ${ }^{24}$ and Holberg et al. ${ }^{18}$ found no difference between the various forms of child care studied. In fact, in both studies, groups of 3 or more children were already at a higher risk than home cared children independently of child-care setting.

\section{Diarrhea}

The association between child-care attendance and diarrhea was explored in the literature by studies using cross-sectional, case-control and follow-up designs. Alexander et al. ${ }^{1}$ used data from the 1981 National Health Survey (US). Parents of children aged less than six years were asked about the occurrence of gastrointestinal illnesses in the previous two weeks. Adjusting for confounders, an odds ratio of 3.5 (1.0-4.8) was found for children under 3 years of age attending child-care centers. For older children, however, no association was demonstrated. The other cross-sectional study was nested in a cohort study ${ }^{3}$. As the morbidity data were not collected in a comparable way for the two groups of child-care center and home children, a series of 5 surveys covering the previous 2 weeks was used for the comparison of diarrhea occurrence. The results, however, were reported as incidence rates. Child-care center children were reported to have a significantly higher risk of diarrhea when compared to home children ( $R R=1.6)$, while children attending childcare homes did not differ from home children.
Two case-controls studies exploring risk factors for acute diarrhea found similar significant effects of child-care attendance. One was carried out in S. Paulo (south-eastern Brazil), where cases and controls were drawn from the emergency room of a municipal hospital ${ }^{5}$. The other study was carried out in Houston (southern USA), and subjects were drawn from a prepaid health care clinic ${ }^{2} .{ }^{9}$ In S. Paulo, the odds ratio for child-care center exposure in the week previous to recruitment into the study was 2.3 ( $\mathrm{p}<0.01)$. In Houston it was 2.4 (1.6-3.7). Other types of child care covered in this study were attendance at child-care homes, child care by relatives, and at mother's day out, which had odds ratios of 2.0 (1.3-3.1), 2.0 (1.2-3.2), and 1.8 (0.84.2) respectively. Also, compared to children cared for at home, children in the first month of enrolment in any child-care setting had an odds ratio of 3.1 (1.85.4) and children enrolled for 1 month or more had an odds ratio of 2.0 (1.4-2.7).

A longitudinal study carried out in France ${ }^{6}$, already discussed in a previous section, found a risk of diarrhea approximately 5 times higher among children attending small child-care centers compared to that of children in child-care homes. The relative risk for children in large child-care centers was about half that for small child-care centers. Another longitudinal study was carried out by Ojembarrena Martínez et al. ${ }^{25}$, with 512 children attending local health centers. Children up to 3 years old in child care were at a risk of diarrhea 2 to 3 times higher than children cared for at home. Estimates were not presented for older children.

A prospective cohort study was carried out in Colombia, by Hillis et al. ${ }^{16}$, with children under 5 years attending 5 public child-care centers and agematched neighborhood controls. They were visited weekly for 22 weeks, when the occurrence of diarrhea was recorded. An overall relative risk of 1.6 (1.42.0) was found for child-care center children compared to children cared for at home. The maximum risk found was for children under 2 years of age ( $R R=2.0,95 \%$ CI 1.5-2.8). The study also suggested that only children attending child-care centers full-time (more than 30 hours per week) were at increased risk of diarrhea. An interesting interaction between child-care center attendance and socioeconomic status was found, with a clear trend to increasing risks from the lower to the higher strata 
(RRs 0.8, 1.6, 1.9, 3.3). This result suggests that for poor families, child-care center attendance may not increase the risk of diarrhea, and might even be a protective environment for the extremely poor.

Again, the studies were consistent in attributing a higher risk of diarrhea to children attending child care. The best designed studies ${ }^{1,5,16,29}$ suggest that the relative risk associated with child care varies between 2 and 3.5 for children under 3 years of age.

Alexander et al. ${ }^{1}$ and Bartlett et al. ${ }^{3}$ found that children in child-care homes were not different from children cared for at home. Reves et al. ${ }^{29}$ found an increased risk for child-care homes, but smaller than that associated with child-care centers. This picture is similar to those relating to respiratory infections. The fact that the position of child-care homes relative to care at home and child-care centers oscillates from study to study is probably related to greater variety in the characteristics and quality of the services offered, and possibly, in the definitions used for childcare homes.

\section{QUESTIONS OF DESIGN AND ANALYSIS}

The studies reviewed here illustrate very well the commonest problems of design and analysis related to research into the health effects of child-care attendance. The most basic problem relates to the very definition of the exposure. Some studies did not define clearly what attendance at child-care centers or in other settings was, especially in terms of the time spent in child care ${ }^{4,6,11,27,32}$. In the other studies, a variety of definitions was used. For example, "at least once per week in the month preceding hospitalization"', and various cut-off points in terms of hours per week (from 4 to 30 hours per week). These differences make the comparison of studies very difficult, and perhaps definitions that are more closely related to the patterns of attendance could be used instead. Most children attend child-care centers regularly full-time or part-time and these patterns could be reflected in the definitions by cut-off points such as 15 hours per week for part-time attendance and 30 hours per week for full-time attendance.

Another important issue in this kind of study is the need to obtain comparable data for attendees and non-attendees of child care, especially in relation to the occurrence of disease. It is much easier to set-up the children's follow-up at the child-care centers, as one person can record morbidity information from a number of children. But, if this is done, there is no way to get comparable information for home children, who are cared for by, usually, by the mother, as happened in two of the studies reviewed ${ }^{3,6}$. The rapport of the respondents with the children will be completely different, and the mothers will have spent most of the day with the child, while the child-care staff will have spent just a few hours every day. A better option is to use the parents as sources of information, and cope with the higher cost involved in getting the same information. The fact that parents of children in child care will have spent less hours with their children is much less of a problem, as they are likely to be informed of any health problem presented by the child.

Finally, there is the problem concerning the hierarchical organization of the children in child-care centers. They are clustered in classes, and classes are clustered in centers. Specially regarding infectious diseases, it is likely that the outcomes are not independent among children in the same class, or even center, as the presence of one sick child is bound to influence the occurrence of disease in the others. The statistical models commonly used make such independence an assumption. This problem is specially important in longitudinal studies, where children are enrolled from a few classes and centers, so that the study ends up with a relatively large number of children in the same group. None of the longitudinal studies reviewed here tackled, or even acknowledged, this problem.

One way of coping with such situations is to analyze the data using a multilevel mode ${ }^{13}$ that can cope with intra-group correlations. The additional difficulty here is that the children cared for at home do not share the same hierarchical organization, making the use of such models much more complex. The simple solution to minimize the effect of such within-class and center correlations is to enroll just a few children from each class and center. Again, the strategy will increase costs as a larger number of centers will be required, and possibly more study staff to do the follow-up.

\section{CONCLUSIONS}

The literature in the area provides a consistent indication that children attending child-care centers 
are at a higher risk of respiratory infections and diarrhea. What is less clear from the available literature is the actual magnitude of the effects involved. The various methodological problems discussed above have probably contributed to the variation of effects reported. Also, this variation is likely to be associated with region, or country, and with quality of care. As a large proportion of the preschool population is already enrolled in child care, both in industrialized and in industrializing countries, and probably an even larger proportion will be involved in the future, it seems to be important that further studies, set up specifically to assess the magnitudes of the risks involved with out-

\section{REFERENCES}

1. Alexander CS; Zinzeleta EM; Mackenzie E.J; Vernon A; Markowitz RK. Acute gastrointestinal illness and child care arrangements. Am J Epidemiol 1990; 131:124-31.

2. Anderson LJ; Parker RA, Strikas RA, Farrar JA, Gangarosa, EJ, Keyserling HL, Sikes RK. Day-care center attendance and hospitalization for lower respiratory tract illness. Pediatrics 1988; 82:300-8.

3. Bartlett AV, Moore M, Gary GW. Diarrheal illness among infants and toddlers in day care centers. II. Comparison with day care homes and households. J Pediatr 1985; 107:503-9.

4. Bell DM, GleiberDW, Mercer AA, Phifer R, Guinter $\mathrm{RH}$, Cohen AJ et al. Illness associated with child day care: a study of incidence and cost. Am J Public Health 1989; 79:479-84.

5. Blake PA, Ramos S, Macdonald KL, Rassi V, Gomes TA, Ivey $\mathrm{C}$ et al. Pathogen-specific risk factors and protective factors for acute diarrheal disease in urban Brazilian infants. J Infect Dis 1993; 167:627-32.

6. Collet JP, Burtin P, Gillet J, Bossard N, Ducruet T, Durr F. Risk of infectious diseases in children attending different types of day-care setting. Epicreche Research Group. Respiration 1994; 61 Suppl 1:16-9.

7. Collet JP, Ducruet T, Floret D, Cogan-Collet J, Honneger D, Boissel JP. Daycare attendance and risk of first infectious disease. Eur J Pediatr 1991; 150:214-6.

8. Diehl I. The prevalence of colds in nursery school children and non-nursery school children. J Pediatr 1949; 34:52-61. of-home child care should be carried out in different regions and countries. It is important that greater attention be devoted to child-care homes, as they are a viable option to child-care centers that may offer lower risks than do the latter. More severe illnesses should be addressed, such as pneumonia. It is only when there is a clear picture as to the risks involved that any necessary, and more radical changes, to child-care services can be proposed, given the probability of the higher costs involved in such improvements. Parallel to that, studies on potential interventions in the child-care environment aimed at reducing morbidity are needed as guides for managers and policy-makers.

9. Doyle A. Incidence of illness in early group and family day-care. Pediatrics 1976; 58:607-13.

10. Fleming DW, Cochi SL, Hightower AW, Broome CV. Childhood upper respiratory tract infections: to what degree is incidence affected by day-care attendance? Pediatrics 1987 ; 79:55-60.

11. Fonseca W, Kirkwood BR, Barros AJD, Misago C, Correia LL, Flores JAM et al. Attendance at day care centers increases the risk of childhood pneumonia among the urban poor in Fortaleza, Brazil. Cad Saúde Pública 1996; 12:133-40.

12. Gardner G, Frank AL, Taber LH. Effects of social and family factors on viral respiratory infection and illness in the first year of life. J Epidemiol Community Health 1984; 38:42-8.

13. Goldstein H. Multilevel statistical models. 2 nd London: Edward Arnold; 1995.

14. Haskins R, Kotch J. Day care and illness: evidence, cost, and public policy. Pediatrics 1986; 77:951-82.

15. Hesselvik L. Respiratory infections among children in day nurseries. Acta Paediatr Scand 1949; 74:96-103.

16. Hillis SD, Miranda CM, Mccann M, Bender D, Weigle K. Day care center attendance and diarrheal morbidity in Colombia. Pediatrics 1992; 90:582-8.

17. Holaday B, Waugh G, Moukaddem VE, West J, Harshman S. Fecal contamination in child day care centers: cloth vs paper diapers. Am J Public Health 1995; 85:30-3, 1995. 
18. Holberg CJ, Wright AL, Martinez FD, Morgan WJ, Taussig LM. Child day care, smoking by caregivers, and lower respiratory tract illness in the first 3 years of life. Group Health Medical Associates. Pediatrics 1993; 91:885-92.

19. Hurwitz ES, Gunn WJ, Pinsky PF, Schonberger LB. Risk of respiratory illness associated with day-care attendance: a nationwide study. Pediatrics 1991; 87:62-9.

20. Jorm, L. R.; Capon AG. Communicable disease outbreaks in long day care centres in western Sydney: occurrence and risk factors. J Paediatr Child Health 1994; 30:151-4.

21. Kershaw JD. Day nurseries. BMJ. 1947; i:782-3.

22. Loda. FA, Glezen WP, Clyde WAJ. Respiratory disease in group day care. Pediatrics. 1972; 49: 428-37.

23. Louhiala PJ, Jaakkola N, Ruotsalainen R, Jaakkola JJ. Form of day care and respiratory infections among Finnish children. Am J Public Health 1995; 85:1109-12.

24. Marbury MC, Maldonado G, Waller, L. Lower respiratory illness, recurrent wheezing, and day care attendance. Am J Respir Crit Care Med. 1997; 155:156-61. 25.

25. Ojembarrena Martinez E, Fernandez de Pinedo Montoya R, Lafuente Mesanza P, Corera Sanchez M. Papel de la guardería y de la escolización precoz en la incidencia de enfermedades infecciosas. An Esp Pedriatr 1986; 45: 45-826

26. Osterholm MT, Reves RR, Murph JR, Pickering LK. infectious diseases and child day care. Pediatr Infect Dis J 1992; 11:S31-41
27. Petersson C, Hakansson A. A retrospective study of respiratory tract infections among children in different forms of day care. Scand J Prim Health Care 1990; 8:119-22.

28. Rasmussen F, Bondestam M. Pre-school children's absenteeism from Swedish municipal day-care centres in 1977 and 1990: methodology and sociodemographic factors. Paediatr Perinat Epidemiol 1993; 7:263-71.

29. Reves RR, Morrow AL, Bartlett AVD, Caruso CJ, Plumb RL, LU BT, Pickering L K. Child day care increases the risk of clinic visits for acute diarrhea and diarrhea due to rotavirus. Am J Epidemiol 1993; 137:97-107.

30. Strangert K. Respiratory illness in preschool children with different forms of day care. Pediatrics. 1976; 57: $191-6$

31. Thompson S. Acute respiratory illness in Adelaide children - the influence of child care. Med J Aust $1991 ; 155: 424$

32. Victora CG, Fuchs SC, Flores JÁ, Fonseca W, Kirkwood B. Risk factors for pneumonia among children in a Brazilian metropolitan area. Pediatrics 1994; 93:977-85

33. Wald ER, Guerra N, Byers C. Frequency and severity of infections in day care: three-year follow-up. $J$ Pediatr 1991; 118:509-14

34. Woodward A, Douglas RM, Graham NM, Miles H. Acute respiratory illness in Adelaide children-the influence of child care [see comments]. Med J Aust $1991 ; 154: 805-8,1991$. 